Article

\title{
Reforming Health, Safety, and Environmental Regulation for Offshore Operations in China: Risk and Resilience Approaches?
}

\author{
Yuan Yang(1) \\ Tilburg Law School and Tilburg Sustainability Centre, Tilburg University, P.O. Box 90153, 5000 LE Tilburg, \\ The Netherlands; y.yang_3@uvt.nl; Tel.: +31-62-661-7114 \\ Received: 25 February 2019; Accepted: 25 April 2019; Published: 7 May 2019

\begin{abstract}
Offshore drilling accidents have triggered regulatory reforms in China. The reforms aim to explore proper regulatory approaches to supervise offshore operations and improve their health, safety and environmental (HSE) performance. This study offers a review on the roles of risk and resilience in managing offshore operations and a well-defined analysis on their integrations with Chinese laws and regulations. The study finds risk and resilience approaches can promote the effectiveness of HSE regulation for offshore operations, while both are difficult to be transposed into legally binding rules in China. To fully develop and implement risk regulation for offshore operations, the study suggests to decentralize China's command-and-control regulatory regime and encourage self-regulation in offshore petroleum companies. Transposing resilience thinking into legal practice is also highlighted so that various regulatory powers can keep proactive and flexible to any possible changes and uncertainties.
\end{abstract}

Keywords: offshore operations; Chinese HSE regulation; risk; resilience; self-regulation

\section{Introduction}

Risks and uncertainties of offshore operations have been increasing in China as innovative technologies develop and petroleum activities move to further and deeper waters. After the occurrence of the 2011 Bohai Bay oil spill accident, China recognized that its command-and-control (CAC) regulatory regime was too prescriptive to fully identify and mitigate risks of offshore operations [1]. As a response, China initiated regulatory reforms, introducing risk analysis into offshore health, safety, and environmental (HSE) regulation. This is similar with the practices of the countries that established the highest safety level of offshore operations. Risk-based regulatory approaches often emerge in response to major offshore accidents [2]. However, risk regulation for offshore operations has not been fully developed under China's CAC regulatory regime. Also, given the complexity of offshore operations, a risk-based approach alone seems to be inflexible and insufficient in dealing with those unknown hazards or sudden threats [3].

The term resilience engineering represents a new way of health, safety, and environmental managements. Compared to risk analysis, which begins with identification of hazards and characterization of probabilities, resilience analysis in offshore engineering may improve the system response to surprises [3]. Resilience approaches accordingly can supplement risk approaches in HSE management systems and contribute to prediction, adaptation and recovery to hazards or disruptive events in offshore operations [4]. In establishing risk regulation for offshore operations, resilience may also create flexible ways for China to resolve conflicts between risk regulation and CAC regulatory regime. To infuse resilience into Chinese HSE regulation, three aspects are worthy of attention: the regulatory flexibility, roles of inspections and enforcement and trust and distrust among the stakeholders. 
This article is conducted based on a broad desk study regarding risk and resilience theories and Chinese laws and regulations on HSE of offshore operations. Research methodology of the article mainly involves qualitative description and legal analysis. Research questions encompass that how China has integrated risk analysis in offshore HSE regulation and to what extent risk and resilience approaches can be implicitly or explicitly embedded in China's CAC regulatory regime. The article reveals the complementary relationship between risk and resilience approaches in managing and regulating offshore operations. It examines the feasibility of integrating risk and resilience in Chinese laws and regulations and discusses obstacles and future prospects of the integrations. Conclusions point out that fully applying risk approaches while infusing resilience thinking in regulatory reforms would be a feasible way for China to facilitate the robustness of offshore HSE regulation.

\section{Challenges for Sustainable Offshore Operations in China}

Offshore petroleum industry has brought significant impacts to human lives, economies, and the natural environment. In the past decade, various oil spill accidents have proved that offshore drilling operations are high risky activities that carried out in harsh working conditions and fragile marine ecosystem [5]. Investigations have shown that challenges for offshore operations arise from multiple factors that have different risk levels (Figure 1). The high-risk factors mainly contain increasing mining activities, environmental changes, new technologies and operational and regulatory failures. To reduce severe impacts of the risk factors, offshore petroleum industry particularly requires sustainable development that can minimum hazards associated with health, safety, and environment.

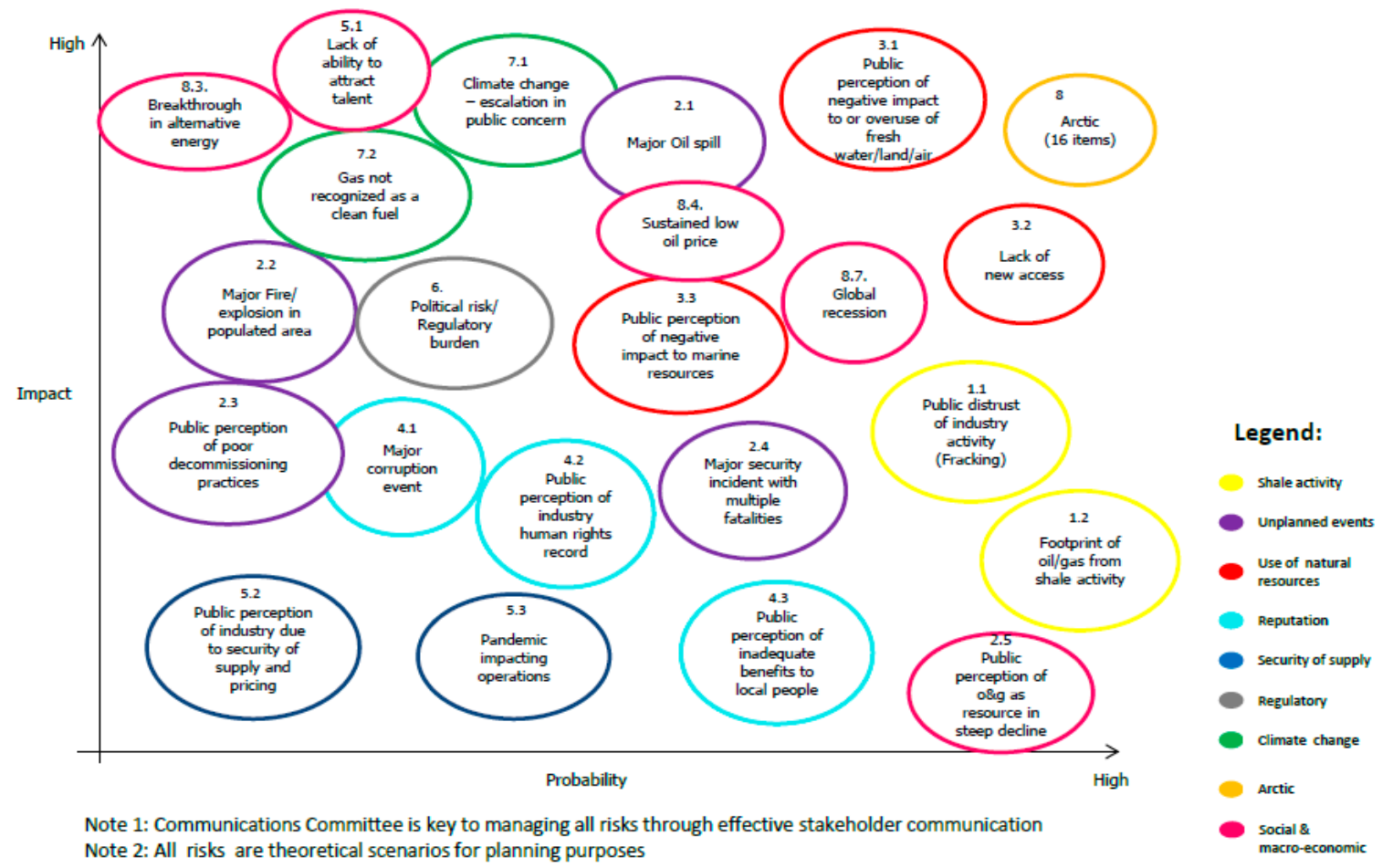
Note 2: All risks are theoretical scenarios for planning purposes

Figure 1. Risks to Global Upstream Industry [6] (Copyright from China National Offshore Oil Corporation).

China has become one of the largest energy consumers in the world. It is estimated that by 2020 the consumption of crude oil will be 12 million barrels a day and natural gas will provide 10 percent of the country's energy. Chinese petroleum companies are faced with the challenges of meeting the expanding energy demands while mitigating risks of their exploitation activities. That means China is transitioning from an industrial society to a risk society [7]. Risks for the Chinese petroleum industry specifically result from complex equipment and workplaces, digital technologies, as well as environmental uncertainties. In the wake of the Bohai Bay accident, Chinese regulators and 
offshore companies recognized that HSE issues in offshore operations may also result from regulatory failures. The accident exposed a series of problems with Chinese regulatory regimes for offshore operations, including fragmented and prescriptive HSE legislation and overlapping or absent functions of ministries and local governments [1]. As such, regulatory challenges are necessarily taken into account in developing sustainable offshore operations.

Sustainable development for offshore petroleum industry depends on whether regulators, petroleum companies and other stakeholders effectively manage and regulate HSE risks. Achieving sustainability also requires operators to conduct HSE management and oversight in the whole offshore operations. Due to different sizes and capabilities of offshore companies, each operator faces the challenge of how to carry out integrated management systems [8]. In the face of regulatory challenges, China also requires more comprehensive laws and regulations to govern risks in offshore operations. Risk and resilience, is this article, are considered to offer new perspectives to improve the quality of HSE managements for offshore operations and provide more ways to regulate offshore petroleum activities.

\section{Risk and Resilience in Managing and Regulating Offshore Operations}

\subsection{Risk-Based Approach}

The risk concept is widely used in a professional or scientific context [9]. As a characteristic of industrialization and modernization, risk contains three conventionally recognized elements: "outcomes that have an impact upon what human's value; the possibility of occurrence (uncertainty); and a formula to combine both elements [10]." This particularly reflects in offshore petroleum industry. The common value to the risk identification in offshore operations arises from economic development, health, safety and environment. Operators have an overall main goal of maximizing these values and avoiding severe accidents [11], with the rapid technological development. This requires probability (i.e., acceptability, tolerability, or intolerability) and consequences of accident scenarios to be analyzed, even though there are hazards unknown or deep uncertainties that risk cannot cope with [12].

Risk analysis is an important tool to develop strategies to prevent accidents and devise mitigation measures [12]. Based on experience and interdisciplinary knowledge to relevant events and activities, risk analysis is conducted to calculate probability of accidents and provide solutions for stakeholders [13]. The main components of risk analysis are risk assessment and risk management [14]. Risk assessment is used to identify natural and technological hazards and to evaluate risk levels [13]. Following outcomes of risk assessment, risk management offers policy options while requiring value assignment and politicized decision-making [14]. To some extent, risk management refers to HSE management. The former focuses more on the technical issues, while the latter addresses human and organizational factors [15]. To carry out offshore operations, risk assessment and risk management usually work together to maintain an acceptable HSE level and provide decision support in implementing risk-reducing measures.

Risk approaches applied in regulation refer to the state action to reduce health, safety, and environmental risks [14]. As the main approach, risk analysis for offshore operations is incorporated into different regulatory regimes. Traditionally, risk analysis is based on a prescriptive regime that applies detailed technological standards to operations and inspections [15]. The prescriptive regime has gradually been replaced by a more goal-and process-oriented regime, putting emphasis on the outcome and overall procedure rather than on detailed standards of offshore activities [15]. Having a strong CAC feature, the prescriptive regime transposes industrial practices into mandatory and enforceable standards in HSE laws and regulations. In contrast, the goal and process-oriented regime makes use of the expertise of both state actors (e.g., regulatory authorities) and non-state actors (e.g., third-party inspectors) in achieving HSE performance. The performance of non-state actors is further related to self-regulation, which highlights internal control capability of operators and voluntary industrial standards, but is unlikely to work alone in governing risks of operations [16]. 


\subsection{Resilience Approach}

A risk-based approach could be defined by the probability and severity of adverse effects that follows poor knowledge and erroneous assumptions [17]. As a consequence, risk analysis for offshore operations may not be able to fully identify all relevant warnings and signals, particularly in the face of emerging threats [11]. Resilience, instead, offers a new approach to embrace unforeseen circumstances and surprises, which can improve risk analysis and avoid severe consequences of offshore accidents. The concept of resilience originates from ecology and can be understood as "the ability of the system to withstand a major disruption within acceptable degradation parameters and to recover within an acceptable time and composite costs and risks [17]." A resilience system is capable of adapting to uncertainties and making those risky systems success in dealing with their inherent complexities [18].

Resilience engineering, as a result, is increasingly developed to complement the risk analysis in offshore petroleum industry. In the face of offshore disasters such as blowouts and explosions, resilience engineering ensures "the design of complex systems that can withstand adverse conditions and recover quickly from disruptions [4]." This represents a new way of thinking about HSE issues in offshore operations. Traditional risk approaches focus on analyzing hazards and failures in offshore operations, while resilience engineering aims to adapt to changes and maintain a normal HSE performance [19]. Although both risk and resilience are essential to sustainable offshore operations, resilience has unique advantages to catastrophe management. This is not to say the latter can substitute the former. Rather, resilience has the complementary attribute that monitor and revise risk models before something goes wrong and respond to regular or irregular threats in a robust and flexible manner [20].

\subsection{Three Dimensions of Resilience in HSE Regulation for Offshore Operations}

Resilience approaches are linked to different modes of offshore risk regulation and interact with different legal traditions, values, institutions and needs, economic and social forces [2]. Since resilience engineering aims to establish a flexible and robust system, flexibility of HSE regulation becomes a criterion to test whether different regulatory modes can foster resilience. CAC regulations can predict and maintain the safety of offshore operations but they weakly handle flexibility [2]. Particularly, prescriptive rules and binding procedures may reduce operators' awareness to emerging hazards and hamper organizational and technological innovations for offshore industry [2]. In contrast, self-regulation focuses on industrial internal controls, which motivates operators to govern their own activities. An internal control system requires each involved party to contribute to ensuring compliance and to improve their expertise to keep pace with technological development [21]. This makes self-regulation consistent with goal- and risk-based rules which are open and flexible to uncertain threats and may facilitate resilience.

The second dimension to test regulatory resilience is whether HSE regulation can handle the mixed roles of inspections and enforcement. The roles of inspections and enforcement in different regulatory modes represent different combinations and relationships between regulators and regulated industries. A CAC regulatory mode focuses on governmental inspections and enforcement, easily causing imbalanced powers and limited communication between regulator and regulated industry. Self-regulatory mode is likely to create balanced powers and to facilitate continuous improvements of industrial standards and best practice [2]. The CAC and self-regulatory modes represent two extremes in the roles of inspections and enforcement. Between them, regulators or inspectors usually take a supervision role while industrial companies ensuring compliance with legal and industrial standards [2]. This combination seems to be more resilient, since fully communication and cooperation can reduce potential conflicts of stakeholders [22].

Regulatory resilience also requires consensus and mutual trust among involved parties. Although the trust "is highly conditional, with unclear boundaries and thresholds for disruption and conflict" [23], balancing trust and distrust is a key factor to promote resilient risk regulation for offshore operations [2]. In specific legal and social contexts, trust is the foundation of a sound safety culture, containing more positive attitudes that can lead to more positive safety behaviors [24]. Investigations show that a failed safety culture could also be a key factor resulting in offshore disasters [25]. Strategically navigating 
safety culture toward resilience would be a solution to reduce regulatory failures in offshore operations. This implies safety culture interacts with HSE regulation [26]. Facilitating resilient culture in law could depend on institutional and regulatory environment.

\section{HSE Laws and Regulations for Offshore Operations in China}

\subsection{Chinese Regulatory Regime for Offshore Operations}

Chinese regulatory regime for offshore operations contains legally binding norms and non-legally binding norms (Table 1). A number of CAC regulations stipulate legally binding rules, requiring the compliance of offshore companies and the enforcement carried by different administrations. Taking safety legislation as an example, the Regulation on Safety of Offshore Oil Operations authorized previous State Administration of Work Safety (SAWS) to conduct an overall supervision on offshore operations [27]. The SAWS established China Offshore Oil Operation Safety Office to implement its supervision duty and to monitor inspections carried out according to standards specified in law [27]. In the contrary, non-legally binding rules are connected with self-regulation, including industrial standards, best practices and company specifications. They usually impose higher HSE criteria on operators than that in legally binding rules. Through continuously developing risk management, non-legally binding rules are more capable of catching up with technological development and more easily update regulatory practices [28].

Table 1. Hierarchy of norms for offshore operations in China.

\begin{tabular}{|c|c|c|}
\hline Hierarchy of Norms & Categories & Examples \\
\hline $\begin{array}{l}\text { Legally binding rules } \\
\text { (CAC regulatory mode) }\end{array}$ & Laws & $\begin{array}{c}\text { Mineral Resources Law } \\
\text { Prevention and Control of Occupational Diseases } \\
\text { Law } \\
\text { Work Safety Law } \\
\text { Marine Environmental Protection Law }\end{array}$ \\
\hline $\begin{array}{ll}\mathrm{R} \\
\mathrm{R}\end{array}$ & $\begin{array}{l}\text { Regulations, regulatory } \\
\text { guidelines and standards }\end{array}$ & $\begin{array}{l}\text { Regulation on the Administration of } \\
\text { Environmental Protection in Offshore Oil } \\
\text { Exploration and Exploitation Detailed Rules for } \\
\text { the Administration of Offshore Oil Safety }\end{array}$ \\
\hline $\begin{array}{l}\text { Non-legally binding rules } \\
\text { (Self-regulatory mode) }\end{array}$ & $\begin{array}{l}\text { Industrial standards, best } \\
\text { practices and company } \\
\text { specification }\end{array}$ & $\begin{array}{l}\text { International Standards under the ISO/TC 67/SC } 7 \\
\text { National Standardization for the Safety of } \\
\text { Offshore Oil and Gas Operations } \\
\text { Internal documents on HSE management of the } \\
\text { key state-owned petroleum companies }\end{array}$ \\
\hline
\end{tabular}

China's risk regulation for offshore operations is embedded in both legally binding rules and non-legally binding rules. Chinese HSE laws and regulations have stipulated risk analysis as the obligation of offshore operators [29]. The risk analysis is required in environmental impact assessment (EIA) of offshore petroleum project, but specific rules have not addressed a comprehensive system containing data collection, standards, procedures and techniques on risk assessment for offshore operations. Emergency response systems (ERS) for oil spill accidents also need risk analysis in external and internal level. External ERS involves risk assessment in national plans and policies, while internal ERS addresses risk management in internal controls of offshore companies. Overall, China's risk regulation for offshore operations shows incomplete and unstable features in a CAC regulatory environment.

Offshore HSE regulation in China involve a number of stakeholders including regulatory authorities, monopolistic state-owned enterprises, private companies, foreign companies and consumers. Based on the CAC regulatory regime, offshore operations are charged with operators, supervised by government and certificated and inspected by third party [30]. Chinese regulators tend to urge risk management and oversight in a historically top-down approach, while instituting "more comprehensive and detailed 
measures that mandate specific internal control procedures" [31]. Regulatory reforms have simplified and integrated multiple departments by establishing the Ministry of Natural Resource, the Ministry of Ecological Environment and the Ministry of Emergency Management. As main regulators, the three departments take responsibilities respectively on development, environment and safety issues of offshore petroleum industry. For different kinds of offshore companies, making an environmental commitment to self-regulation may lead to better HSE performance and motivate them to implement "effective means of being green" [32]. This implies that self-regulation internal control may play an important role in HSE management for Chinese petroleum activities.

\subsection{The Status of CNOOC in Chinese HSE Regulation}

The offshore petroleum industry in China used to adopt a joint exploitation mode between state-owned companies and foreign enterprises. China National Offshore Oil Corporation (CNOOC) has exclusive right to cooperate with foreign enterprises and is responsible for exploration, exploitation, production, and sale of offshore petroleum resources. Chinese offshore industry accordingly shows a non-marketed based feature in its development, which causes a low competition among petroleum companies. Since state-owned companies and Chinese government work together for social benefits and economic development, CNOOC and regulators seem more like one stakeholder and have a high level of trust with each other. In contrast, the non-marketed based development and CAC regulatory regime are easily cause distrust between non-state companies and Chinese regulators. This can be demonstrated by the unequal accountability imposed on foreign operators and CNOOC in Bohai Bay accident [1]. To improve HSE performance of offshore operations, the Chinese government has also initiated market reform for petroleum industry and motivated stakeholders to take alternative measures such as risk analysis and emergency training other than merely to comply with prescriptive rules.

The early joint exploitation mode has facilitated the technological development of the Chinese petroleum industry. Although CNOOC is state-operated, it commits to develop innovative technology to enhance the exploitation and production efficiencies. In 2017, CNOOC invested RMB 7.29 billion in science and technology, of which RMB 2.79 billion was for research and development (R\&D) [33]. Some achievements of the R\&D have been transposed into international standards [33], indicating that CNOOC steadily improves its independent innovation ability. The technological development actually proposes high requirements on expertise and experience of working team of CNOOC [30]. To some extent, personnel performance in terms of health, safety, and environment may determine the effect of risk management for offshore operations. As the future petroleum industry becomes more intelligent, less accidents may be led by human factors, but safety culture is still important in activating HSE awareness of stakeholders to take alternative approaches for minimizing risks of offshore operations.

\subsection{Regulating HSE Management System for Offshore Operations}

China has introduced international HSE standards for sustainable offshore operations, such as the ISO 9000 series for quality management and the ISO 14000 series for environmental management systems. Modeled on these standards, Chinese offshore companies can establish an HSE management system (HSEMS) to achieve their commitments in conducting business, maintaining safe and healthy work while protecting environment at all times [34]. The system usually operates in a circular procedure, which includes planning organizational structure and HSE work, implementing HSE plan, checking HSE performance and adjusting relevant processes (Figure 2). It shows that a HSEMS for offshore operations in China particularly focuses on the compliance, risk identification and evaluation, emergency response management, HSE accountability and communication, equipment and facilities management. By measuring and promoting HSEMSs continuously, offshore companies aim to minimize risks in operations and to improve the results in the fields of quality, health, safety, and environment. 


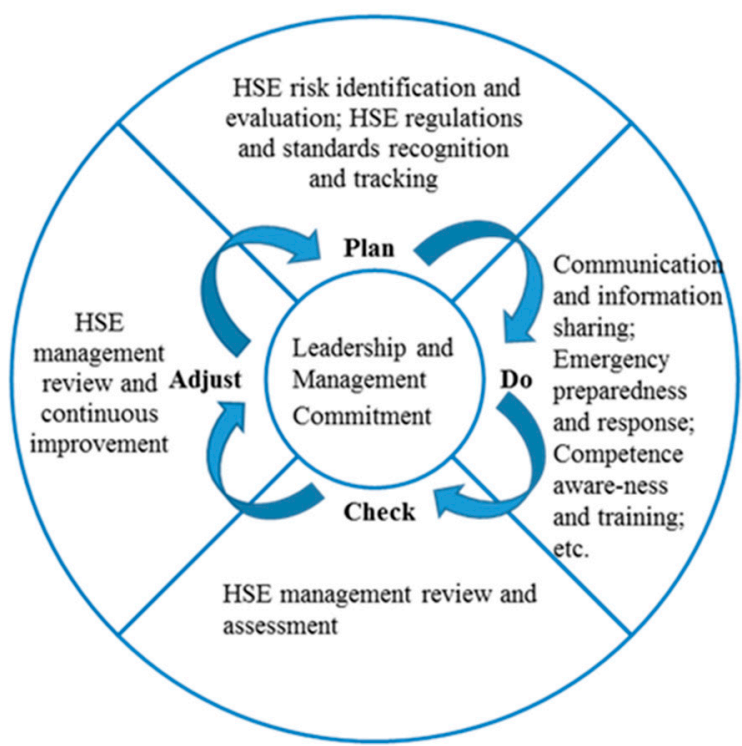

Figure 2. Overview of health, safety, and environmental (HSE) management system.

Overall, HSEMS is a tool based on risk management that ensures HSE policy and principles are applied consistently to offshore operations. By collecting human and organizational data, a mature HSEMS conducts quantitative risk assessment (QRA) to help operators evaluate safety of offshore operations and optimize production [35]. The QAR has been fully adopted by petroleum companies in countries with high HSE level such as Norway and U.K., while it lacks systematical solution and research tools in Chinese HSE management practice [36]. Without the application of QAR, Chinese HSEMSs are weak to support operators in their decision-making and to provide regulators with optimal policy options. Non-technical factors may supplement the weakness of Chinese HSEMSs. The factors mainly include risk communication and teamwork among workers and stakeholders, which cannot work well without a transparent safety culture. This goes beyond the compliance to laws and regulations and promotes each employee to work in a manner that truly enhances safety. For China, the petroleum industry is particularly experiencing a transform of safety culture from external awareness and compliance to internal maximally protecting people and environment.

Currently, regulating HSEMSs of the Chinese petroleum industry mainly relies on international and national standards. International Organization for Standardization specifies requirements for occupational health and safety management systems in the standard ISO 45001 . The ISO 45001 takes into account other international standards, like Occupational Health and Safety Assessment Series 18,000 (OHSAS18000), aiming to assist organizations in managing risks and improving health and safety performance. Based on them, China has enacted an Occupational Health and Safety Management System Specification, which contains general principles and procedures for risk management but not addresses specific guidelines or designs for the petroleum industry. While health, safety and environment managements have close relationships in offshore operations, they have various standards internationally and domestically and have not been taken as an integral system by these standards. Industrial practice in China, on the contrary, has increasingly established complete systems containing health, safety and environment managements, which will improve the effectiveness of minimizing risks and preventing accidents in offshore operations.

\section{Integrating Risk and Resilience Approaches into Chinese HSE Regulation for Offshore Operations}

\subsection{Developing Risk Regulation for Offshore Operations}

Although China has taken regulatory reforms to minimize risks in offshore operations, offshore risk regulation seems hardly to be established in a CAC environment. The regulatory reforms follow a 
top-down mode. People's congress and government firstly initiate plans and make principles and standards in HSE laws and regulations. Then regulators and inspectorates ensure the compliance and enforcement by issuing specific rules and motivating non-state actors to actively govern HSE risks of offshore operations. Risk-based regulatory approaches were firstly introduced in the Environmental Protection Law (EPL) in 2014, which stipulates:

The State shall establish and improve environment and health monitoring, investigation and risk assessment systems; encourage and organize research on environmental quality impacts to public health and take measures to prevent and control diseases related to environmental pollution. [37]

This could be a fundamental rule for China to develop offshore risk regulation, which can cover environment-related risks in industrial development. Together with risk analysis required in EIA of petroleum projects, risk regulation for offshore operations has not clarified risk categories, techniques and procedures of risk assessment. This easily leads to weak compliance and enforcement under China's CAC regulatory regime and further results in implementation gaps. To comprehensively govern risks in productive activities, the State Council enacted the 13th Five-Year Plan on Safety Production, proposing to establish capacities of inspection, information monitoring, risk prevention, occupational disease management, technological support, emergency response and culture service [38]. The policy may become a guidance for China to further develop risk regulation on HSE of offshore operations.

In effect, risk regulation for offshore operations in China is legally allowed to be developed in the form of self-regulation [39]. For example, CNOOC is authorized to exclusively cooperate with foreign companies, which can catch up with the latest technologies and industry best practices in HSE management. In practice, industrial self-regulation is not thorough since the state-owned companies are developed in a non-market-based environment that lacks competition and transparency. Furthermore, Chinese HSE legislation does not require offshore companies to reduce risks to a level as low as reasonably practicable, which may slow down the motivation and willpower of state-owned companies to have continuous internal controls and developments.

Apart from offshore companies, social organizations can also self-regulate management activities. According to the Administrative Licensing Law, "the organization managing public affairs under a law or regulation shall, within the authorized scope, implement the administrative license in its own name [40]". The China Academy of Safety Sciences and Technologies and China Occupational Safety and Health Association, for example, as branches of previous SAWS, can make supports or supplements to technological development, HSE education and training, work safety inspection and risk management. For Chinese offshore industry, stepping toward self-regulation of the professions is now driven by governmental authority, regulatory bodies and companies themselves [39]. However, in China, there is a tension between risk rules in self-regulation with bureaucratic performance in CAC governance [41]. This leaves an uncertainty that whether China can fully develop risk regulation on HSE of offshore operations and ensure its effective implementation.

With respect to HSE management of offshore operations, China has not transformed HSEMS as a legal obligation for offshore operators. Although HSEMSs have been widely applied to the Chinese petroleum industry, few information can illustrate how the systems interact with regulation in preventing major offshore accidents. This may because a HSEMS is usually consistent with goal-setting regulatory standards, while risk rules embedded in Chinese regulatory regime rely on CAC prescriptive standards. However, Chinese petroleum companies do use internal goals to develop their HSEMSs. By making goals in quality, health, safety and environment managements and evaluate the performance of each department, CNOOC adjust its HSEMS and facilitate the integration of HSEMS and Chinese laws and regulations. Besides, state actors have transposed risk assessment of HSEMSs to regulatory standards. In 2017, China National Health Commission Enacted Guidelines for Occupational Health Risk Assessment of Chemicals in the Workplace, which would promote the development of the HSEMS in law. 


\subsection{Assessing Resilience in Chinese HSE Regulation}

Resilience offers an innovative direction for China to interact with offshore risk regulation and to further reform offshore HSE regulation. As one of the dimensions of resilience, the extent of flexibility of Chinese HSE regime reflects whether China has the condition to apply resilience approaches to risk regulation for offshore operations. Since China's offshore risk regulation must be understood in a CAC regulatory context, regulators have more responsibilities than operators and other stakeholders to handle disruptive events [41]. However, Chinese regulators may have insufficient expertise and experience to adapt to new economic conditions and innovative technologies which is essential for resilience. Meanwhile, too prescriptive regulatory regime may reduce the ex-ante measures to emerging risks that are also required by organization resilience [2]. Therefore, an internal control system in petroleum companies and public organizations, like the HSEMS of CNOOC, could be increasingly important since it leaves more flexibilities for each participant to ensure that their activities are compliance with HSE laws, regulations and policies.

The second dimension to assess resilience is the roles of inspections and enforcement in Chinese modes of offshore risk regulation. Chinese HSE laws and regulations require offshore operators, inspectors and other involved parties to be in compliance with regulatory standards and prescriptive inspections. Implementing the standards and inspections mainly relies on governmental enforcement and sanctions, which is consistent with CAC regulatory regime that can maintain a certain HSE level but is hard to identify risks dynamically. Risk regulation for offshore operations, on the one hand, is developed under a CAC environment that easily causes imbalance in power relations and limits the communication between regulators and offshore industry; on the other hand, alternative modes of offshore risk regulation like self-regulation is increasingly adopted by Chinese petroleum companies and organizations, which allows inspectors and the professional and scientific community to devise higher industrial standards.

Balancing trust and distrust among regulators, regulated industries and other stakeholders also influences resilience in risk regulation for offshore operations [28]. The unequal power relationships as illustrated in China's offshore risk regulation may undermine trust among different stakeholders, while the dominant role of state-owned petroleum companies actually decreases the adversarial relationship between regulators and regulated industry. Chinese regulators seem to have overconfidence on state-owned petroleum companies but less trusts on non-state actors, which may bring difficulty to implementing risk analysis in offshore operations, and further lead to inequality in accountability in the face of industrial disasters [42]. Accordingly, trust among stakeholders tends to be unstable and unbalanced, which may further undermine resilience in HSE regulation for Chinese petroleum industry.

To facilitate resilience in HSE regulation, Chinese regulators strength and balance the trust by promoting stakeholder dialogue and cooperation [43]. Specifically, public participation is taken as an important tool for effective communication in risk management as well as resilience engineering [44]. Emergency response systems for industrial accidents are also developed at all levels so that stakeholders can cooperate with each other. In addition, trust interacts with safety culture in the Chinese petroleum industry, consultancy, politicians and the public. Following the Bohai Bay accident, Chinese regulators have gradually recognized a sound safety culture should be widely spread so that each participant can make commitments and take proactive measures to reduce HSE risks and achieve better HSE performance in offshore operations [45].

\subsection{Remaining Obstacles and Future Prospects}

Overall, regulatory reforms in the aftermath of Bohai Bay accidents adopt risk and resilience approaches in different degrees. Risk analysis is stipulated in Chinese HSE laws and regulations to reduce major hazards and management failures in offshore operations. Meanwhile, resilience measures like public participation in EIA are encouraged to supplement risk rules, in case uncertain threats or unexpected events occur. China develops risk regulation for offshore operations under a CAC regulatory regime, combining governmental inspections and enforcement and industrial self-regulation. 
However, Chinese regulators used to emphasize rule-compliance more than risk management, which hampers motivations of each participant taking all measures to prevent major offshore accidents. To balance different powers and concerns and achieve better HSE performance, China's risk regulation for offshore operations should move towards a more decentralized and self-regulatory framework.

There are several challenges for China to establish a hybrid regulatory regime that is suitable to develop offshore risk regulation. Firstly, self-regulation in the petroleum industry does not fit into Chinese CAC regime very well, since it focuses on internal control and voluntary compliance. A wide range of self-regulation can improve the flexibility of Chinese regulatory regime towards any changes and advanced technologies, but may lead to weak enforcement [39]. Secondly, HSEMSs in industrial practice are difficult to be transposed into stable legal standards, because the systems need to dynamically track hazards and emerging risks. Due to different technique and facility conditions of offshore operations, both Chinese and foreign operators hardly implement and evaluate HSEMSs in unified standards. Thirdly, the dominant market position of state-owned companies may hamper competitions in Chinese petroleum industry. This accompanies with opaque information disclosure and insufficient communication in decision-making, which influences HSE performance of offshore operations.

Given the obstacles of reforming HSE regulatory regime, China attempts to integrate multiple approaches to supplement risk regulation for offshore operations. To relieve conflicts between CAC and self-regulatory modes, China improves the flexibility of risk regulation by stipulating environmental protection target accountability and performance evaluation system in the EPL [37]. This allows regulators and inspectors to actively develop and assess legal standards to match industrial standards, best practices and professional judgement. To facilitate competition and improve HSE performance in offshore petroleum industry, China deepens market reforms by introducing non-state capital and explores new technology and business areas. This process is hopefully to strengthen communications and balance trust among diverse stakeholders. Recognizing the importance of values and norms in reducing risks and uncertainties in offshore operations [46], Chinese regulators and petroleum companies also make efforts to develop safety culture. This would be an opportunity to infuse resilience thinking into law-making in the future.

\section{Conclusions}

Risk and resilience provide feasible ways for China to reform HSE regulation for offshore operations. As mutual-supplementary approaches, risk aims to reduce regulatory failures in accident prevention, while resilience helps regulators, operators and organizations transfer their attentions from "what is wrong" to "what is right". Risk analysis for offshore operations has been introduced in Chinese laws and regulations, while its implementation depends on HSEMSs that are under internal controls of offshore petroleum companies. This demonstrates self-regulation rather than CAC regulatory mode may better facilitate risk regulation for offshore operations. Nevertheless, reforming Chinese HSE regulation does not mean to abandon the CAC regulatory regime that used to ensure governmental enforcement and inspections. Regardless of regulatory modes, developing offshore risk regulation needs to convert risk management to rule compliance that both are vital components of Chinese HSE strategies [47]. In the face of the conflicts of the regulatory transformation, resilience may create flexible approaches to strengthen communications and cooperation of stakeholders. A resilient regulatory regime for offshore operations should be capable of balancing the roles of regulators, inspectors and petroleum companies, so that each participant can adapt to changes arising from environment, innovative technologies, and market reforms. In the long run, China needs to explore more feasible ways to integrate risk and resilience approaches in HSE laws and regulations. An integrated regulatory regime by then would balance regulatory powers and stakeholders' trust, so that China can guarantee sustainable offshore operations that maximize the protection of marine environment.

Funding: This research is funded by China Scholarship Council (CSC) No. 201406220117 and Tilburg Law School for the PhD project of Yuan Yang. 
Acknowledgments: The author is grateful to the editors of this special issue and the three anonymous reviewers. Special thanks to Jonathan Verschuuren, Arie Trouwborst and relevant colleagues at Tilburg Law School; to the relevant participants in the 16th Annual Colloquium of the IUCN Academy of Environmental Law "The Transformation of Environmental Law and Governance: Innovation, Risk and Resilience".

Conflicts of Interest: The author declares no conflict of interest.

\author{
Abbreviations \\ CAC command and control \\ CNOOC China National Offshore Oil Corporation \\ EIA environmental impact assessment \\ EPL Environmental Protection Law \\ ERS emergency response system \\ HSE health, safety and environmental \\ HSEMS health, safety and environmental management system \\ QRA quantitative risk assessment \\ R\&D research and development \\ SAWS State Administration of Work Safety
}

\title{
References
}

1. Yang, Y. Regulatory Regimes for Preventing Major Accidents in Offshore Operations: Evolution of Approaches in the United States and China. Georget. Environ. Law Rev. 2019, 31, 341-364.

2. Lindøe, P.H. Risk Regulation and Resilience in Offshore Oil and Gas Operation. In Law and the Management of Disasters: The Challenge of Resilience, 1st ed.; Herwig, A., Simoncini, M., Eds.; Routledge: London, UK, 2016.

3. Park, J.; Seager, T.P.; Rao, P.S.C.; Convertino, M.; Linkov, I. Integrating Risk and Resilience Approach of Catastrophe Management in Engineering Systems. Risk Anal. 2013, 33, 356-366. [CrossRef]

4. Sarwar, A.; Khan, F.; Abimbola, M.; James, L. Resilience Analysis of a Remote Offshore Oil and Gas Facility for a Potential Hydrocarbon Release. Risk Anal. 2018, 38, 1601-1617. [CrossRef]

5. Moroni, D.; Pieri, G.; Tampucci, M. Environmental Decision Support Systems for Monitoring Small Scale Oil Spills: Existing Solutions, Best Practices and Current Challenges. J. Mar. Sci. Eng. 2019, 7, 19. [CrossRef]

6. CNOOC HSE Management Practice-Wills. Available online: http://www.willis.com/documents/energy/2015/ Willis_CNOOC_HSE_Management_Practice-EN.pdf (accessed on 20 February 2019).

7. Qin, T. Challenges for Sustainable Development and Its Legal Response in China: A Perspective for Social Transformation. Sustainability 2014, 6, 5075-5106. [CrossRef]

8. Huang, L.; Liang, D. Development of Safety Regulation and Management System in Energy Industry of China: Comparative and Case Study Perspectives. Procedia Eng. 2013, 52, 165-170. [CrossRef]

9. Aven, T. The Risk Concept-Historical and Recent Development Trends. Reliab. Eng. Syst. Saf. 2012, 99, 33-44. [CrossRef]

10. Renn, O. Risk Governance: Coping with Uncertainty in a Complex World; Earthscan: London, UK, 2008.

11. Aven, T.; Krohn, B.S. A New Perspective on How to Understand, Assess and Manage Risk and The Unforeseen. Reliab. Eng. Syst. Saf. 2014, 121,1-10. [CrossRef]

12. Khakzad, N.; Khan, F.; Amyotte, P. Quantitative risk analysis of offshore drilling operations: A Bayesian approach. Saf. Sci. 2013, 57, 108-117. [CrossRef]

13. Renn, O. A Generic Model for Risk Governance: Concept and Application to Technological Installations. In Risk Governance of Offshore Oil and Gas Operations; Lindøe, P.H., Baram, M., Renn, O., Eds.; Cambridge University Press: Cambridge, UK, 2014.

14. Hutter, B.M. Risk, Regulation, and Management. In Risk in Social Science; Taylor-Gooby, P., Zinn, J.O., Eds.; Oxford University Press: London, UK, 2006.

15. Aven, T.; Vinnem, J.-E. Risk Management with Application from the Offshore Petroleum Industry; Springer: London, UK, 2007.

16. Baram, M.; Lindøe, P.H. Modes of Risk Regulation for Prevention of Major Industrial Accidents. In Risk Governance of Offshore Oil and Gas Operations; Lindøe, P.H., Baram, M., Renn, O., Eds.; Cambridge University Press: Cambridge, UK, 2014. 
17. Aven, T. On Some Recent Definitions and Analysis Frameworks for Risk, Vulnerability, and Resilience. Risk Anal. 2011, 31, 515-522. [CrossRef]

18. Aven, T. Risk Assessment and Risk Management: Review of Recent Advances on Their Foundation. Eur. J. Oper. Res. 2016, 253, 1-13. [CrossRef]

19. Vinnem, J.-E. Offshore Risk Assessment, Vol. 1: Principle, Modelling and Application for QRA Studies, 3rd ed.; Springer: London, UK, 2014.

20. Linkov, I.; Bridges, T.; Creutzig, F.; Decker, J.; Fox-Lent, C.; Kröger, W.; Lambert, J.H.; Levermann, A.; Montreuil, B.; Nathwani, J.; et al. Changing the Resilience Paradigm. Nat. Clim. Chang. 2014, 4, 407-409. [CrossRef]

21. Bang, P.; Thuestad, O. Government Enforced Self-Regulation: The Norwegian Case'. In Risk Governance of Offshore Oil and Gas Operations; Lindøe, P.H., Baram, M., Renn, O., Eds.; Cambridge University Press: Cambridge, UK, 2014.

22. Buzzanell, P.M.; Houston, J.B. Communication and Resilience Multilevel Applications and Insights- $A$ Journal of Applied Communication Research forum. J. Appl. Commun. Res. 2018, 46, 1-4. [CrossRef]

23. Kringen, J. Contested Terrains in Risk Regulation: Legitimacy Challenges in Implementation Processes. In Risk Governance of Offshore Oil and Gas Operations; Lindøe, P.H., Baram, M., Renn, O., Eds.; Cambridge University Press: Cambridge, UK, 2014.

24. Flin, R.; Burns, C. The Role of Trust in Safety Management. Hum. Factors Aerosp. Saf. 2004, 4, $277-287$.

25. David G Broadbent. Building A Resilient Safety Culture. Available online: http://www.transformationalsafety. com/documents/Building_Resilient_Safety_Cultures_TS.pdf (accessed on 20 February 2019).

26. Kongsvik, T.; Gjøsund, G.; Vikland, K.M. HSE culture in the petroleum industry: Lost in translation? Saf. Sci. 2016, 81, 81-89. [CrossRef]

27. Regulation on the Safety of Offshore Oil Operations (Issued by the State Administration of Safety on 7 February 2006; revised on 29 August 2013, 26 May 2015).

28. Engen, O.A.; Lindøe, P.; Hansen, K. Power, trust and robustness-The politicization of HSE in the Norwegian petroleum regime. Policy Pract. Health Saf. 2017, 15, 145-159. [CrossRef]

29. According to Marine Environment Protection Law of the People's Republic of China (2016 Revision) (The 24th Session of the Standing Committee of the 5th National People's Congress, 23 August 1982, in force 1 March 1983; revised in 1999, 2013, 2016).

30. Cheng, Z.; Cheng, K.; Yang, G.; Xiaojun, H.; Huang, X. HSE Management for China Offshore Drilling Project. In Proceedings of the International Petroleum Technology Conference 2013, Beijing, China, 26-28 March 2013.

31. Ho, V.H. Corporate Governance as Risk Regulation in China: A Comparative View of Risk Oversight, Risk Management, and Accountability. Eur. J. Risk Regul. 2012, 4, 463-475. [CrossRef]

32. Lin, H.; Zeng, S.; Ma, H.; Chen, H. Does Commitment to Environmental Self-regulation Matter? An Empirical Examination from China. Manag. Decis. 2015, 53, 932-956. [CrossRef]

33. Technology Innovation. For Example, CNOOC Led the Drafting of the ISO 18647 Oil and Gas Industry-Specifications for Offshore Modular Drilling Rigs on Fixed Platforms, Which Was Released as an International Standard. CNOOC Gas \& Power Group won the CWC LNG Technological Innovation Award 2017. Available online: http://www.cnooc.com.cn/col/col6491/index.html (accessed on 20 February 2019).

34. Sun, Y.; Wang, N. Health Safety and Environmental Management Systems in China National Petroleum Corporation. Available online: https://www.irbnet.de/daten/iconda/CIB10334.pdf (accessed on 20 February 2019).

35. Wang, Y.F.; Li, Y.L.; Zhang, B.; Yan, P.N.; Zhang, L. Quantitative Risk Analysis of Offshore Fire and Explosion Based on the Analysis of Human and Organizational Factors. Math. Probl. Eng. 2015, 2015, 537362. [CrossRef]

36. Lv, Y.; Wei, W. Risk Assessment of Oil Spill on the Offshore Platform. Mar. Sci. 2014, 38, 33-38. (In Chinese)

37. Environmental Protection Law of the People's Republic of China (2014 Revision) (The 11th session of the Standing Committee of the 7th National People's Congress, 26 December 1989, in force 26 December 1989; revised in 2014), Article 39, 57, 26, 28.

38. The General Office of the State Council Issued Notice on the Safe Production of the 13th Five-Year Plan. Available online: http://www.gov.cn/zhengce/content/2017-02/03/content_5164865.htm (accessed on 20 February 2019).

39. Philipsen, N.; Weishaar, S.E.; Xu, G. (Eds.) Market Integration: The EU Experience and Implications for Regulatory Reform in China; Springer: London, UK, 2015. 
40. The Administrative License Law of the People's Republic of China (The 4th session of the Standing Committee of the 10th National People's Congress, August 27, 2003, in force July 1, 2004), Article 23.

41. Johnson, T. Environmental Risks and Authoritarian Resilience in China. In Risk, Resilience, Inequality and Environmental Law; Hutter, B.M., Ed.; Edward Elgar: Cheltenham, UK, 2017.

42. Mills, R.W.; Reiss, D.R. The Role of Trust in the Regulation of Complex and High-risk Industries: The Case of the U.S. Federal Aviation Administration's Voluntary Disclosure Programs. In Trust in Regulatory Regimes; Six, F., Verhoest, K., Eds.; Edward Elgar: Northampton, UK, 2017.

43. Wang, H. Dialogue Strategies for Socio-ecological Resilience and Sustainability in China. In Risk, Resilience, Inequality and Environmental Law; Hutter, B.M., Ed.; Edward Elgar: Cheltenham, UK, 2017.

44. Zhang, L.; He, G.Z.; Mol, A.P.; Lu, Y.L. Public Perceptions of Environmental Risk in China. J. Risk Res. 2013, 16, 195-209. [CrossRef]

45. Global Agenda Council on the Future of Oil \& Gas. Trust Challenge Facing the Global Oil \& Gas Industry. In Proceedings of the World Economic Forum, Colony, Geneva, Switzerland, April 2016.

46. Mearns, K. Values and Norms-A Basis for a Safety Culture. In Risk Governance of Offshore Oil and Gas Operations; Lindøe, P.H., Baram, M., Renn, O., Eds.; Cambridge University Press: Cambridge, UK, 2014.

47. Hopkins, A. Risk-management and Rule-compliance: Decision-making in Hazardous Industries. Saf. Sci. 2011, 49, 110-120. [CrossRef]

(C) 2019 by the author. Licensee MDPI, Basel, Switzerland. This article is an open access article distributed under the terms and conditions of the Creative Commons Attribution (CC BY) license (http://creativecommons.org/licenses/by/4.0/). 